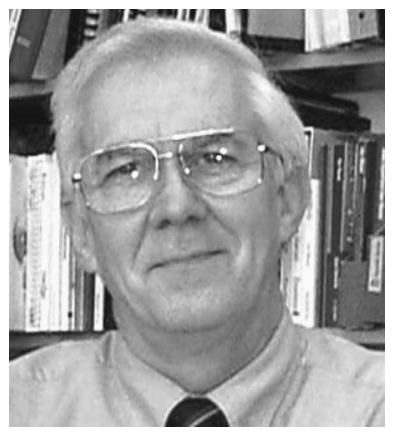

\section{My Research Colleague}

Some time ago, after nine years of working on diffractive optics, I decided that I would have to stop. It wasn't that there weren't any problems to be done. In fact, I had several ideas for some devices that employed the use of crossed phase gratings and other moiré effects generated by placing two phase elements in close proximity. These systems presented some really neat optical engineering problems to be solved. But I teach and do research in a school of physics.

I probably could have continued the research on the problems if there were still some master's-level students around. But as I noted some time ago, such students have completely disappeared here in physics. So, stuck with a laboratory that turned out diffractive elements with modest-sized $(10-\mu \mathrm{m})$ features within days of an initial design, I decided to give the equipment to one of my last doctoral students for use for undergraduate research projects and as a springboard for his own research.

This move was partly occasioned by rearrangements in my life so that I could carry out my duties as SPIE president during 2000. But according to my research notebook, there were two other diversions in 1999 that used my time: the potential SPIE/OSA merger and a CD on lens design for SPIE. With both of those obligations out of the way and because I had handed over the editorship of this journal for that year, I found that I had some time on my hands and I began to get itchy. It was clear that I couldn't stop doing research after more than 35 years. I had started in laser Raman spectroscopy, then wandered through Brilliouin spectroscopy to optomechanical design before alighting for almost a decade in diffractive optics. I wanted back in, but I didn't want to do diffractive optics. Also, it seemed neither realistic nor prudent to try to crank up another laboratory from scratch, since I am within a few years of retirement.

So I looked around the school to see if there was a colleague that I could work with. As it turned out, someone had recently joined our faculty, who was developing and using interesting optical systems. Rick Trebino had developed a technique at Sandia Labs for measuring ul- trafast pulses, called FROG, which stands for frequency resolved optical gating. It is a technique that records both the nonlinear correlation of an ultrafast pulse with its replica and the spectrum of the result. These data can be analyzed to determine the temporal and spectral variations and phases of a pulse. It's a very clever and useful technique in the field of ultrafast optics, for which SPIE awarded Rick the Edgerton Award in 1999.

There was a problem with working in Rick's lab, however. My son, Patrick, was one of his thesis students. So, before approaching Rick, I felt obligated to ask Pat if he would mind my working in the research group. When I broached the topic, he said it was OK with him without a second thought. Rick welcomed me with open armsespecially when he found I was not going to add anything to his research budget.

Earlier Rick and I had talked about applying diffractive optics to ultrafast optics, but their incredible dispersion (in the visible, diffractive elements have a $V$-number of -3.45 !) makes it difficult to use them. So, as I joined the group, I was a minister without portfolio, but it didn't take long for an opportunity to present itself. The idea, generated by Mark Kimmel, the Ultrafast Lab manager, was to provide more sensitivity than the current devices, but also to rapidly acquire the data. By introducing a scanned beam into a more conventional version of the device, it becomes a hybrid of two earlier versions of FROG devices. As is the usual practice in such research, after tinkering with some preliminary geometries, I set up a test bed late one night. This, of course, was on the eve of the final day for submitting an abstract for a meeting. Pat came in and we aligned and tweaked, looking for a faint but expected signal that would appear for a short distance within the scanned region. We found it, and early in that morning submitted the abstract electronically. Considering how crude our geometry was when we made that initial measurement, we were very lucky to have found the signal at all. By the time the paper was delivered, substantial refinements had simplified our alignment and adjustments.

One of the most satisfying aspects of this research has been working with Pat as a colleague. He has never had a problem telling me when he thought I was all wet, so 
there are no parent-child conflicts. He is fun to work with and tough when it comes to data analysis and crafting conclusions. It is interesting to watch Pat working as a journeyman researcher. Last October, along with Rick and Mark, my son and I gave a paper on the research and last month we published the research as a paper in Optics Letters. Whatta kick!

Donald C. O'Shea Editor 